\title{
Review on Genetic Variability Study in Leafy Vegetable Crops for Agro Morphological Traits
}

\author{
Ousman Yimer \\ Ethiopian Institute of Agricultural Research, Holetta Agricultural Research Center \\ PO Box 31, Holetta, Ethiopia
}

\begin{abstract}
Vegetables make up a major portion of the diet of humans in many parts of the world and are considered essential for well-balanced diets. Leafy vegetables crops are one group of vegetable crops which used mainly for their leaves whether eaten raw or cooked. Variability refers to the presence of difference among the individuals of a population. The components of variability include phenotypic variation, genotypic variation, environmental variation, heritability, genetic advance etc. In different leafy vegetables collection study there exist a wide variation between them, this variation can be useful for improvement of vegetables crops with the help of partitioning variances. Vegetable breeders should be able to determine the relative importance or magnitude of genetic and environmental variances. There is lack of information in vegetable breeding, especially leafy vegetables. The objective of this paper is to summarize different research papers on leafy vegetable crops breeding for different agro morphological traits to show the genetic variability component phenotypic variability, genotypic variability, heritability and genetic advance study.
\end{abstract}

Keywords: genetic advance, genotypic variability, Heritability, leafy vegetables, phenotypic variability

DOI: $10.7176 / \mathrm{JNSR} / 9-17-01$

Publication date:September $30^{\text {th }} 2019$

\section{Introduction}

Vegetables/ leafy vegetables/ make up a major portion of the diet of humans in many parts of the world and are considered essential for well-balanced diets since they supply vitamins, minerals, dietary fiber, and phytochemicals and have been associated with improvement of gastrointestinal health good vision, and reduced risk of heart disease, stroke, chronic diseases such as diabetes, and some forms of cancer (Keatinge et al. 2010).

A world vegetable survey showed that 402 vegetable crops are cultivated worldwide, representing 69 families and 230 genera. Leafy vegetables crops are one group of vegetable crops which used mainly for their leaves whether eaten raw or cooked, e.g. lettuce, mustard, amaranth, cabbage, kale, celery and etc. Vegetable crops, of which the leaves or young leafy shoots are consumed, were the most common group of vegetables utilized ( $53 \%$ of the total) (Kays 2011).

Among vegetables there is a wide range of natural breeding systems, including in breeders and out breeders, as well as those which are partial in breeders and partial out breeders. There are insect and wind-pollinated forms and for those crops in which sex forms vary, there are monoecious and dioecious types. While breeding methods vary according to the natural breeding system of a crop, in any breeding program the breeder requires genetically variable material with which to work (AVRDC 1983). Given suitable selection and evaluation techniques, as well as knowledge of the natural breeding system so that appropriate breeding strategies may be followed, improved varieties can be developed. Vegetable improvement has to address and satisfy the needs of both the consumer and the farmer. The major objectives of vegetable improvement programme are different for farmers from consumers (Dias 2011).

There is lack of information in vegetable breeding information, especially leafy vegetables. The objective of this paper is to summarize information on genetic variability, phenotypic and genotypic variability, heritability and genetic advance study in different leafy vegetable crops genotypes.

\section{Literature Review}

\subsection{Genetic Variability Components}

\subsubsection{Genotypic and phenotypic variability}

Variability refers to the presence of difference among the individuals of a population. The components of variability include phenotypic variation, genotypic variation, environmental variation, heritability, genetic advance etc. It is a known fact that genotypes within the species exhibit variation in different metric traits and components of yield. The genetic variation can only be useful for crop improvement with the help of partitioning variances. Plant breeders should be able to determine the relative importance or magnitude of genetic and environmental variances. Genetic variability is the existence of differences among individuals due to differences in their genetic composition and/or the environment in which they are raised (Allard 1960; Falconer \& Mackay 1996). Genetic variability is considered as important aspect which taken into account before planning for any breeding program. The success of any selection program depends largely upon the magnitude of genetic variability present in the 
population (Yadav et al. 2016).

The variation within each genotype is due to the environment that is two organisms with the same genotype may not necessarily be identical in color because nutrition, physiological state, and many other variables influence the phenotype. If the character expression of two individuals could be measured in an environment identical for both, differences in expression would result from genetic control and hence such variation is called genetic variation (Welsh 1990; Falconer \& Mackay 1996).

The phenotypic expression of the plant is mainly controlled by genetic makeup of plant and its interaction with environment. It is necessary to partition the observed phenotypic variability into its heritable and nonheritable components with suitable parameters (Robinson et al. 1949). Knowledge of genetic parameters such as genotypic coefficient of variation (GCV) and phenotypic coefficient of variation (PCV) are useful biometrical tools for understanding the extent of genetic variability in base population which is a prerequisite for crop improvement (Swati et al. 2014).

In study Esiyok et al. (2011) reported high PCV and GCV for petiole length, petiole width, petiole thickness, lamina length, lamina width and medium for both PCV and GCV were recorded for leaf weight in study of swisschard genotypes. Varalakshmi and Devaraju (2010) in study of Indian spinach observed high PCV and GCV for leaf number, plant height, individual and total plant weight. While they recorded medium GCV and High PCV for leaf petiole length. Hasan et al. (2013) in study genetic variability of different amaranthus genotypes reported high PCV and GCV for leaf number, leaf width, marketable yield, and he reported medium PCV and GCV for plant height.

In genetic variability study of leafy amaranthus Akaneme \& Ani (2013) reported the highest PCV and GCV values computed for parameter, leaf length, plant height, canopy cover, days to flowering and high PCV and medium GCV for leaf width finally the authors reported high PCV and low GCV for petiole length. Lyngdoh et al. (2017) in study of genetic variability in green mustard genotypes reported the highest PCV and GCV values for plant height and medium PCV and GCV for leaf yield per plant but low for both PCV and GCV recorded for leaf width. In similar vegetable crops Buhroy et al. (2017) reported the highest PCV and GCV values computed for leaf length and leaf breath, medium PCV and GCV for plant height, plant length, leaf weight and number of leaf per plant.

Mutoni (2010) evaluated 47 Ethiopian mustard genotypes for leaf yield and yield related traits in Tanzania and reported highest variability was observed for leaf yield, days to $50 \%$ maturity, leaf petiole length, leaf length, leaf width, leaves/plant, plant height, canopy diameter, petiole width.

\subsubsection{Heritability and genetic advance}

In general sense, heritability specifies the proportion of the total variability that is due to genetic causes, or the ratio of genotypic variance to the total variance. It is a good index of the transmission of characters from parents to their offspring (Allard 1960; Phani et al. 2015). To estimate the heritability serves as a useful guide to the breeder and also the breeder is able to appreciate the production of variation that is due to genotypic (broad sense heritability) or additive (narrow sense heritability) effects (Khanorkar \& Kathiria, 2010). Whereas, genetic advance measures genetic gain under selection.

Buhroy et al. (2017) reported high heritability for petiole length, leaf length, leaf width, total leaf weight, plant height, green yield per plant, number of leaf per plant, leaf breadth in 10 leafy genotypes of amaranths. Akaneme \& Ani (2013) found medium estimates of heritability in broad for leaf width and leaf length in amaranths genotypes. Varalakshmi \& Devaraju (2010) observed high estimates of heritability in broad sense for leaf number, leaf weight, petiole length, leaf length and total edible plant parts 11 genotypes of Indian spinach. Tejaswini et al. (2017) reported high heritability for leaf length, leaf width, number of leaf per plant, plant height, total leaf yield, protein and iron content in 29 genotypes of vegetable amaranths.

Esiyok et al. (2011) reported high heritability for petiole length, petiole width, petiole thickness, lamina length, lamina width and leaf weight in study of swisschard genotypes. Research results revealed that the estimates of heritability were observed as high for wrapper leaf, net yield, diameter of head, days to harvest, plant spread in cabbage (Thakur \& Vidyasagar 2016). Lyngdoh et al. (2017) in study of genetic variability in green mustard genotypes reported the highest heritability in broad for leaf length, leaf width, plant height, leaf yield per plant but low for both PCV and GCV recorded for leaf width.

Genetic advance is defined as the difference between the mean genotypic value of the selected lines and the mean genotypic values of the original population before selection (parental population) or it indicates the potentiality of selection at a particular level of selection intensity. As Johnson et al. (1955) suggested that both heritability and genetic advance are important selection parameters. Heritability estimates along with genetic advance are normally more helpful in predicting the gain under selection (i) high heritability accompanied with high genetic advance indicates that most likely the heritability is due to additive gene effects and selection may be effective, (ii) high heritability accompanied with low genetic advance indicates non-additive gene action and selection for such traits may not be rewarding, (iii) low heritability accompanied with high genetic advance reveals that the characters is governed by additive gene effect the low heritability is being exhibited due to high 
environmental effects, selection may be effective in such case and (iv) low heritability accompanied with low genetic advance indicates that the character is highly influenced by environmental effects and selection would be ineffective. The high heritability would be a close correspondence between the genotypic and phenotypic variations due to relatively small contribution of the environment to the phenotype expression of the trait (Singh 1990).

Tejaswini et al. (2017) investigated 19 characters of 29 genotypes of vegetable amaranthus shows high heritability. Moreover, that high heritability ( $>80 \%)$ coupled with high genetic advance $(>20 \%)$ as percent of mean registered for plant height, total foliage leaf yield, leaf length. Bozokalfa et al. (2017) reported that heritability values were generally high for some of characters under the study. Estimates high $\mathrm{H}^{2}$ coupled with high GAM obtained for parameter number of branches of Swiss chard.

Esiyok et al. (2011) high heritability ( $>80 \%)$ coupled with high genetic advance $(>20 \%)$ as percent of mean registered for petole length, lamina length, petiole thickness, petiole width, plant height and leaf length. Buhroy et al. (2017) reported that heritability values were generally high for some of characters under the study. Estimates high $\mathrm{H}^{2}$ coupled with high GAM obtained for parameter petiole length, number of leaf per plant, leaf length, leaf breadth, plant height and green yield per plant in study of vegetable amaranthus.

In the study, high heritability accompanied with a high genetic advance for marketable head yield, gross head weight and net head weight revealed the role of additive gene action and thus, a high genetic gain is expected from selection for these traits. The gross and net weight of head was found to be highly variable and important characters, which might be responsible for wide range in yield potential (Thakur \& Vidyasagar, 2016). In addition to this high heritability $(>60 \%)$ coupled with high genetic advance $(>20 \%)$ as percent of mean was observed for leaf number, leaf weight, plant height and total plant leaf weight Varalakshmi \& Devaraju (2010). Hasan et al. (2013) investigated 17 genotypes of vegetable amaranthus and reported high heritability coupled with high genetic advance as percent of mean registered for plant height, total foliage leaf number, leaf width.

\section{Conclusion}

Leafy vegetables make up a major portion of the diet of humans in many parts of the world and are considered essential for well-balanced diets. Leafy vegetables crops are one group of vegetable crops which used mainly for their leaves whether eaten raw or cooked. Variability refers to the presence of difference among the individuals of a population. The components of variability include phenotypic variation, genotypic variation, environmental variation, heritability, genetic advance etc. In different leafy vegetables collection study there exist a wide variation between them, this variation can be useful for improvement of vegetables crops with the help of partitioning variances. Vegetable breeders should be able to determine the relative importance or magnitude of genetic and environmental variances. The above literature supported paper summarize different research papers on leafy vegetable crops breeding for different agro morphological traits which show the genetic variability component phenotypic variability, genotypic variability, heritability and genetic advance study. From literature there exists wide variation in different leafy vegetable collections, which is important for improvement of vegetable crops.

\section{References}

Akaneme, F.I. and Ani, G.O. (2013). Morphological assessment of genetic variability among accessions of amaranthus hybridus. World Applied Sciences Journal, 28 (4): 568-577

Allard, R.W. (1960). Principles of Plant Breeding. John Willey and Sons. Inc. New York, USA.

Bozokalfa, M.K., Yagmur, B., Esyok, D. \& Asçiogul, T.K. (2017). Genetic variability and association pattern among quantitative nutritional traits in swisschard (Beta vulgaris subsp. L. Var. Cicla) accessions and its implication for breeding. Genetika, 46(2): 505-514.

Buhroy, S., Saraswathi, T. \& Ramalingam, J. (2017). Genetic basis of yield and quality variations in vegetable amaranths (A. tricolor) to identify the promising genotypes. International Journal of Current Microbiology and Applied Sciences, 6(4): 2104-2111

Dias J. S. and Ryder E. J. (2011). World vegetable industry: Production, breeding, trends. Horticulture Reviews 38: 300-356.

Esiyok, D., Bozokalfa, M.K. \& Asciogul, T.K. (2011). Variability, heritability and association analysis in plant traits of swisschard (Beta vulgaris subsp. Cicla). Genetika, 43(2): 239-252.

Falconer, D.S. and Mackay, T.F.C. (1996). An Introduction to Quantitative Genetics. $4^{\text {th }}$ edition. Longman Group Limited, London.

Hasan, M., Akther, C. A. \& Raihan, M. S. (2013). Genetic variability, correlation and path analysis in stem amaranths (Amaranthus tricolor L.) genotypes. The Agriculturists, 11(1): 1-7.

Innes, N.L. (1983). Breeding Field Vegetables. Asian Vegetable Research and Development Center, 10th Anniversary Monograph Series. Shanhua, Taiwan, Republic of China.

Johnson, H. W., Robinson, H.F. \& Comstock, R.E. (1955). Genotypic and phenotypic correlation in soybean and their implication in selection. Agronomy Journal, 47: 314-318. 
Kays, S.J. (2011) Cultivated vegetables of the world: A multilingual onomasticon. Wageningen Academic Publishers, Wageningen. http://dx.doi.org/10.3920/978-90-8686-720-2

Khanorkar S.M and Kathiria, K. B. (2010). Heterobeltiosis, inbreeding depression and heritability study in okra (Abelmoschusesculentus (L.) Moench). Electronic Journal of Plant Breeding, 1(4): 731-741.

Lyngdoh, Y., Kanaujia S. P. \& Shah, P. (2017). Genetic variability, characters association and path coefficient analysis in green mustard (Brassica juncea L.) genotypes. International Journal of Recent Scientific Research, 8: 19388-19391.

Muthoni, J. (2010). Characterization of Ethiopian mustard (Brassica carinata A. Braun) lines for vegetative agro morphological traits at Arusha, Tanzania. Journal of Horticulture and Forestry, 2(1): 001-006.

Phani, K.M., Hameedunnisa, B.A., Manohar, R. \& Kumar, N.S. (2015). Estimation of heritability and genetic advance in okra (Abelmoschus esculentus L. Moench). Plant Archives, 15(1): 489-491.

Robinson, H. F., Comstock, R. E. \& Harvey, P. H. (1949). Estimates of heritability and degree of dominance in corn. Agronomy Journal, 41: 253-259.

Singh, B.D., (1990). Plant Breeding. Kalyani Publishers, New Delihi, India.

Swati, B., Reena, N., Meenakshi, R. \& Jain, P.K. 2014. Genetic variability in okra (Abelmoschus esculentus L. Moench). An International Quarterly Journal of Environmental Sciences, 6: 153-156.

Tejaswini, N., Reddy, K.R., Saidaiah, P. \& Ramesh, T. (2017). Studies on variability, heritability and genetic advance in vegetable amaranth (Amaranthus tricolor L.) genotypes. International Journal of Applied Agricultural and Horticultural Science, 8 (5): 1071-1075.

Thakur, H. and Vidyasagar (2016). Estimates of genetic variability, heritability and genetic advances for yield and horticultural traits in cabbage (Brassica oleracea var. capitata L.). Journal of environmental and bio science, 30(1): 155-157.

Varalakshmi and Devaraju. (2010). Genetic variability in Indian spinach (Basella alba L.). Journal of Horticultural Science, 5 (1): 21-24.

Welsh, J.R. (1990). Fundamentals of Plant Genetic and Breeding, John Wiley and Sons. New York.

Yadav Rajee, V. K., Syamal, M.M., Kumar Manish, Pandiyaraj, P., Nagaraju kattula \& Kaushal, A. (2016). Correlation and path analyses for fruit yield and its component traits in okra (Abelmoschus esculentus L. Moench) genotypes. International Journal of Agriculture Sciences, 9(13): 4063-4067. 